\title{
Nitric oxide level and von Willebrand factor (vWF) secretion are not candidate markers of endothelial cell dysfunction in adenosine triphosphate (ATP) depleted endothelial cells
}

\author{
Mohaddeseh Behjati $^{1 *}$, Mohammad Hashemi $^{1}$, Mohammad Kazemi ${ }^{2}$ and Mansoor Salehi ${ }^{3}$ \\ ${ }^{1} \mathrm{MD}$, Isfahan University of Medical Sciences, Isfahan, Iran. \\ ${ }^{2}$ M.Sc. in Molecular Biology, Isfahan University of Medical Sciences, Isfahan, Iran. \\ ${ }^{3} \mathrm{PhD}$ in Molecular Biology, Isfahan University of Medical Sciences, Isfahan, Iran.
}

Accepted 14 March, 2011

\begin{abstract}
Endothelial cells under physiological conditions can alter energy balance by alteration in synthesis, metabolism and transport of adenosine triphosphate (ATP), which failed during endothelial cell dysfunction. ATP depleted endothelial cells are unable to perform their physiological functions as energy dependent protein secretion. Isolated human umbilical vein endothelial cells (HUVEC) from fresh umbilical cords were treated with $10 \mathrm{mM}$ 2-deoxyglucose and $0.1 \mathrm{pg} / \mathrm{ml}$ of oligomycin for $6 \mathrm{~h}$ to induce ATP depletion. Nitric oxide (NO), von Willebrand factor (vWF), lactate dehydrogenase (LDH) release and trypan-blue exclusion were compared between treated and untreated cells. We observed a slight decrease in nitric oxide levels $(P=0.09)$ and vWF $(P=0.395)$ in the setting of $49.36 \%$ ATP depletion. There was no significant change in LDH release and cell viability between treated and untreated cells $(P$ $>0.05$ ). Since vWF exocytosis is an energy consuming process, decreased secretion of vWF in the isolated near-half percent of ATP depletion is not seemingly at odds. The application of vWF exocytosis fades as a candidate marker for ATP depletion induced injury, in cultured endothelial cells. Nitric oxide level and vWF secretion are not candidate markers of endothelial cell dysfunction in isolated partial ATP- depleted HUVECs. Measures such as arachidonic acid synthesis may be better alternatives.
\end{abstract}

Key words: Endothelial cell dysfunction, adenosine triphosphate (ATP) depletion, nitric oxide, von Willebrand factor (vWF).

\section{INTRODUCTION}

Endothelial cells under physiological conditions can alter energy balance by alteration in the synthesis, metabolism

${ }^{*}$ Corresponding author. E-mail: behjati@med.mui.ac.ir. Fax: +98311222255.

Abbreviations: ATP, Adenosine triphosphate; ox-LDL, oxidized low-density lipoprotein; vWF, von Willebrand factor; HUVEC, human umbilical vein endothelial cells; EDTA, ethylenediaminetetraacetic acid; 2DG, 2-deoxyglucose; OG, oligomycin; PBS, phosphate buffered saline; LDH, lactate dehydrogenase; KATP, adenosine triphosphate dependent potassium channels; RBECs, rat brain capillary endothelial cells. and transport of adenosine triphosphate (ATP) (Buxton et al, 2001; Arakaki et al., 2003). These cells release Purinergic nucleotides that are then hydrolyzed to adenosine diphosphate (ADP) and adenosine by the act of ectonucleotidase (Kolosova et al., 2005). The released ATP acts as a protective agent in the maintenance of endothelial cell integrity via its barrier-keeping function (Kolosova et al., 2005). The generated adenosine is a potent autacoid, which prohibits untoward platelet activation and thrombus formation (Bassenge, 1989). In addition, adenine nucleotides modulate the release of endothelial-derive relaxing factors and hence play an important role in flow-mediated arterial vasoregulation (Choi and Barakat, 2004).

In the process of endothelial cell dysfunction, herald 
mechanism toward atherosclerosis and endothelial cells fail to keep their energy balance state. This alteration is due to oxidative mitochondrial dysfunction, oxidized lowdensity lipoprotein (ox-LDL) and inflammatory or hypoxic injuries (McCully, 2009; Schmitt, 1995; Hultén and Levin, 2009). This energy depletion put cells in energy crisis which mutually results in further mitochondrial damage by accumulation of reactive species. The inactivated ectonucleotidase activity, mainly CD39, results in increased vascular level of ADP and limited bioavailability of adenosine, which is associated with increased platelet aggregation and vasoconstriction (El-Omar et al., 20058; Burnstock, 1987). Energy depletion makes cells susceptible to further injuries, a synergistic factor, which threatens health of the cell and its neighbors; hence they lose energy for defense. Depletion of ATP, major consequence of ischemia disrupts the normal transmembrane ionic gradients and ion channels, which leads to accumulation of sodium and calcium in intracellular and $\mathrm{K}$ in extracellular space (Hinshaw et al., 1988; Siesjö, 1992; Köppel et al., 1998). The impaired function of ATPregulated channels, detrimental in the control of cell membrane polarization, is evident by depolarized state of dysfunctional cells (Figura et al., 2009).

Endothelial cell dysfunction is associated with reduced nitric oxide (NO) release (Florea and Blatter, 2008). Increased plasma levels of von Willebrand factor (vWF) were also detected in endothelial cell dysfunction, but it is not evaluated in endothelial cells exposed to isolated ATP depleted endothelial cells. As a matter of fact, vWF secretion from endothelial cells is an ATP dependent process, which is expected to be inhibited in ATP depleted endothelial cells (Vischer, 2006). Based on these data, it seems unreasonable to use vWF release, a widely used marker of endothelial cell dysfunction, in each setting. Application of VWF as a marker of endothelial cell dysfunction seems questionable in cultured endothelial cells, with the absence of platelets and ischemic tissue, as other sources of vWF.

Therefore, this study was performed to evaluate the role of ATP depletion on the NO levels and VWF secretion in endothelial cells, and their efficacy as candidate markers of endothelial cell dysfunction in vitro.

\section{MATERIALS AND METHODS}

\section{Cell isolation and culture}

Human umbilical vein endothelial cells (HUVEC) were isolated from fresh umbilical cords as described previously. Briefly, human umbilical cords were obtained by written consent; with approval from Institutional review committee of Isfahan University of Medical Sciences. Cells were cultured in M199 culture medium (Gibco-BRL, Scotland) in T25 flasks coated with gelatin (1\%). Confluent monolayers were passed using Trypsin/ ethylenediaminetetraacetic acid (EDTA) (Sigma- Aldrich, St. Louis, MO). Morphology of HUVEC monolayer was examined by a phase contrast microscope (Motic digital microscopes equipped with Moticam digital camera/software). Verification of endothelial cell identity was also performed by the expression of CD31 (PECAM) on their surface which was measured by flow cytometry analysis after staining with phycoerythrin-conjugated murine monoclonal anti-human antibodies (eBiosciences, San Diego, CA, U.S.A.). All experiments were carried out in triplicates on the primary cultures in their third passage.

\section{Induction of ATP depletion}

HUVECs were treated with $10 \mathrm{mM}$ 2-deoxyglucose (2DG), a glycolytic inhibitor, and $0.1 \mathrm{pg} / \mathrm{ml}$ of oligomycin (OG), a respiratory chain inhibitor, to induce ATP depletion and incubated at room temperature, in phosphate buffered saline (PBS). The applied dose of these agents was based on the dose-response curve of these compounds (data not shown). According to the previous study carried out by Revtyak et al. (1992), the simultaneous application of these agents were associated with partial ATP-depletion without induction of apoptosis or necrosis. So with the application of this method, the desired ATP-depletion amount is less than $50 \%$. After $6 \mathrm{~h}$, culture media was removed and cells were washed with PBS.

\section{Assay of cellular ATP/ADP}

In order to assess the induced ATP depletion, cellular ATP, ADP and ADP/ATP ratio were measured by the ApoSENSOR ${ }^{\text {TM }}$ ADP/ATP Ratio Assay Kit (Biovision, USA), in induced and uninduced cells in 96-well plates. Adenine nucleotides were measured by quantified chemiluminescent signals read out using a CentroLIA LB 961 plate Luminometer (Berthold Technologies, Germany). The quantified signals were expressed in $\log _{10}$ relative light units (RLU). Morphological changes after ATP depletion were assessed by phase contrast microscope and viable cells were counted after staining with trypan blue.

\section{Lactate dehydrogenase (LDH) assay}

In order to determine membrane disintegration and increased permeability, LDH levels were measured in test and control cells. The supernatant LDH of treated and untreated HUVECs in 96-well plates were assayed, based on the reduction of $\mathrm{NAD}^{+}$at $339 \mathrm{~nm}$, using DGKC Kit (Parsazmun, Iran).

\section{NO measurements}

$\mathrm{NO}$ in cell-conditioned medium was measured indirectly by quantification of nitrites, using the total nitric oxide and nitrate/nitrite parameter assay kit according to manufacturer's instructions (R\&D). NO measurement was performed in both treated and untreated cells.

\section{vWF measurements}

Extracellular vWF was measured in HUVECs in 96-well plates before and after ATP depletion using Asserachrom vWF Kit according to manufacturer's instructions (Diagnostica Stago, France).

\section{ATP-dependent ion transport}

In order to evaluate the induced ionic changes after ATP depletion in HUVECs, the extracellular $\mathrm{Na}$ and $\mathrm{K}$ were measured by emission flame photometry before and after ATP depletion. 


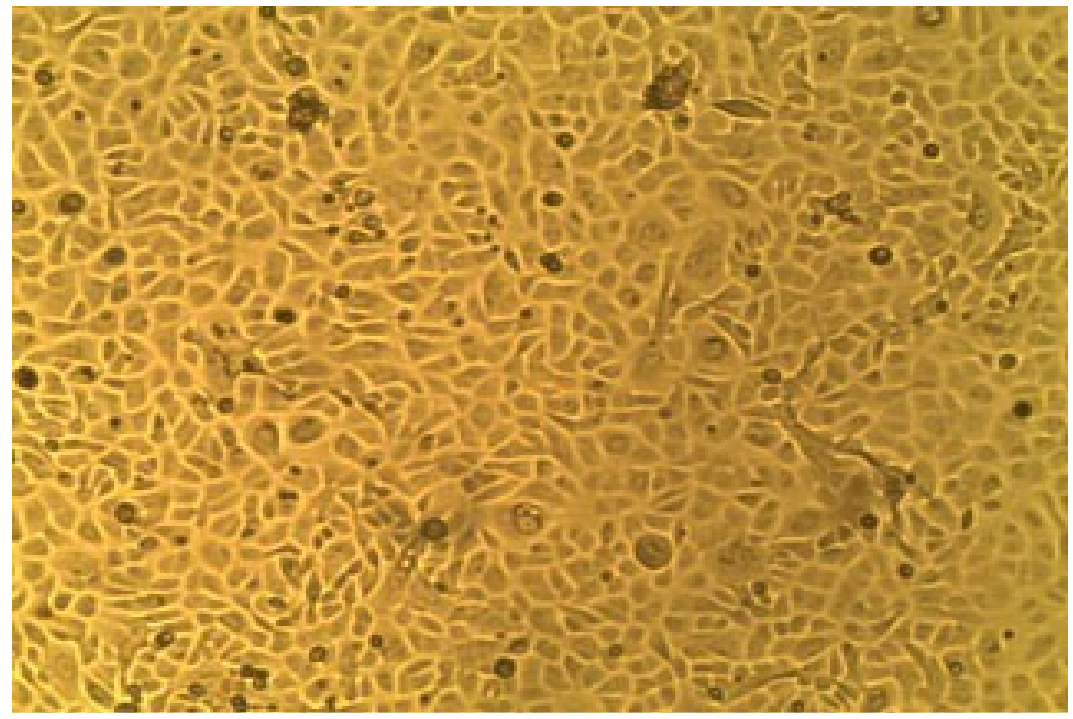

Figure 1. Round morphology of human umbilical vein endothelial cells depicted by phase-contrast microscope.

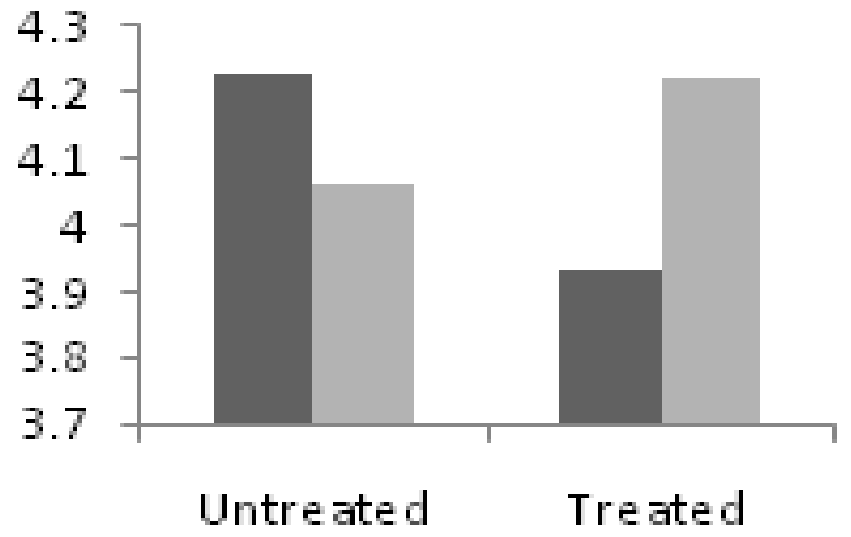

Figure 2. Influence of 2-deoxyglucose and oligomycin treatment on cellular ATP and ADP levels in HUVECs. The amounts of ATP (black bars) and ADP (grey bars) were assessed in HUVEC cells before and after $6 \mathrm{~h}$ of treatment with 2-deoxyglucose and oligomycin. The results are expressed as $\log _{10}$ relative light units (RLU) (mean for three repeats).

\section{Statistical analysis}

Data representations and statistical tests were made with paired samples Student's t-test using the Statistical Package for the Social Sciences (SPSS) software Ver. 15. P-value less than 0.05 was considered to be significant.

\section{RESULTS}

\section{Induction of ATP depletion by simultaneous application of 2DG and OG}

The study was based on the HUVEC cells, well known cells in terms of endothelial cell injury and dysfunction. Cells were verified as endothelial cells by their polygonal cobblestone morphology. Phase contrast microscopic photographs of the cultured endothelial cells are shown in Figure 1 . Flow cytometry results demonstrated that cells were stained positively with anti-CD31 antibody. By simultaneous application of 2DG and OG, $49.36 \%$ ATP depletion was induced in the treated cells and cellular ADP demonstrated a $45 \%$ increase in treated when compared with untreated cells. ADP/ATP ratio was 0.51 in untreated cells which increased to 3.33 after treatment with 2DG and OM. These data are mostly in favor of growth arrest (Figure 2). There was no difference in the cell number between treated and untreated cells, counted by trypan blue exclusion within $15 \mathrm{~min}(92.66 \pm 1.11 \mathrm{vs}$. $96.36 \pm 0.53 \%$ per $40 \mathrm{~mm}$ dish, $P=0.071, \mathrm{n}=3$ ). After 6 $h$ of ATP depletion, some endothelial cells appeared round and retracted. Only a few numbers of ATP-depleted endothelial cells were detached from the culture media and large gaps were seen between endothelial cells. There was no difference in LDH release between treated and untreated cells $(7.40 \pm 0.56$ vs. $7.55 \pm 0.07 \mathrm{IU} / \mathrm{L}, \mathrm{P}=$ $0.75, \mathrm{n}=3$ ), which is in favor of intact membrane and absence of the necrotic events in ATP depleted endothelial cells (Table 1).

\section{ATP depletion decreases NO levels and vWF secretion in HUVECs}

There was a slight decrease (16.32\%) in NO levels between induced and un-induced endothelial cells (7.23 \pm 1.13 vs. $8.64 \pm 0.85 \mu \mathrm{m} / \mathrm{L}, \mathrm{P}=0.09, \mathrm{n}=3$ ). In addition, our results demonstrated a marginal decrease $(15.73 \%)$ in secreted vWF between treated and untreated cells 
Table 1. Effect of ATP depletion on NO level, vWF secretion, LDH release and extracellular $\mathrm{Na} / \mathrm{K}$ of human umbilical vein endothelial cells.

\begin{tabular}{lcc}
\hline \multirow{2}{*}{ Parameter } & \multicolumn{2}{c}{ Mean \pm SD } \\
\cline { 2 - 3 } & Before & After \\
\hline $\mathrm{NO}$ & $8.64 \pm 0.85$ & $7.23 \pm 1.13$ \\
$\mathrm{VWF}$ & $0.087 \pm 0.008$ & $0.105 \pm 0.023$ \\
$\mathrm{LDH}$ & $7.55 \pm 0.07$ & $7.40 \pm 0.56$ \\
$\mathrm{Na}$ & $158.3 \pm 1.52$ & $138.3 \pm 1.52^{*}$ \\
$\mathrm{~K}$ & $4.40 \pm 0.1$ & $3.83 \pm 0.05^{*}$ \\
\hline
\end{tabular}

Primary cultures of HUVECs in 96-well plates were incubated for $6 \mathrm{~h}$ in the absence and presence of $10 \mathrm{mM}$ 2-deoxyglucose (2DG) and 0.1 $\mathrm{pg} / \mathrm{ml}$ oligomycin (OG) in PBS buffer, $\mathrm{pH} 7.4$ at $37^{\circ} \mathrm{C}$. NO level, vWF secretion, $\mathrm{LDH}$ release and extracellular $\mathrm{Na} / \mathrm{K}$ were assessed before and after ATP depletion. Data are expressed as the mean \pm S.D for three repeats. * denotes $\mathrm{P}<0.05$.

$(0.0876 \pm 0.0087$ vs. $0.1056 \pm 0.023885 \mu \mathrm{m} / \mathrm{L}, \mathrm{P}=0.395$, $\mathrm{n}=3$ ) (Table 1).

\section{Altered ionic gradient in ATP depleted HUVECs}

A significant decrease in extracellular $\mathrm{Na}$ was observed between induced and un-induced endothelial cells (138.33 \pm 1.52 vs. $158.33 \pm 1.52 \mathrm{mEq} / \mathrm{L}, \mathrm{P}=0.006, \mathrm{n}=3)$. This decrease $(12.63 \%)$ is in parallel with inhibition of $\mathrm{Na} / \mathrm{K} / \mathrm{ATP}$ ase pump. Interestingly, a significant decrease (12.95\%) in extracellular $\mathrm{K}$ level was also seen in ATP depleted cells when compared to normal ATP level cells (3.8333 \pm 0.057 vs. $4.4000 \pm 0.100 \mathrm{mEq} / \mathrm{L}, \mathrm{P}=0.023, \mathrm{n}=$ 3) (Table 1).

\section{DISCUSSION}

In our experiment, vWF factor was slightly decreased $(15.73 \%)$ in ATP-depleted endothelial cells. Hence, it is considered as a marker of endothelial cell dysfunction and we expected it's secretion to be increased. vWF functions (Holmsen, 1994) and its exocytosis from endothelial cells are shown to be an ATP-dose dependent process (Hegeman et al., 1998) and Consequently, after ATP depletion, vWF exocytosis will be impaired and decreased vWF secretion in this setting, is explainable by its energy dependent protein exocytosis.

Enhanced vWF exocytosis is seen in the HUVECs exposed to isolated acute hypoxia, in contrast to human retinal endothelial cells which showed decreased vWF secretion under oxygen-glucose deprivation (Kim et al., 2007). It seems that the secretion of vWF in response to endothelial cell stimulants is different by endothelial cells with various origins, but the importance of this difference needs to be determined. High levels of cytokines in vitro were not able to raise the secretion of VWF in treated endothelial cells, which hints the diverse effects of diffe- rent stimuli on vWF exocytosis (Zavoico et al., 1989). Considering energy depletion as a cellular insult with effects on VWF secretion, the effects of isolated metabolic inhibition on the vWF exocytosis pattern in HUVECs needs to be determined. ATP and its metabolites exert an agonist-induced exocytosis of vWF (Parker and Gralnick, 1997). Contrarily, ATP depletion acts as an antagonistinhibited exocytosis of vWF (Dorner et al., 1990). So, enhanced vWF exocytosis from dysfunctional endothelial cells is not attributable to energy crisis and we suggest that other stimuli such as membrane shedding may provoke it. On the other hand, activated platelets and reperfused ischemic tissues may be source of secreted vWF which are absent in studies on HUVECs. Also, for endothelial cells, it has been demonstrated that vWF secretion in platelets is an ATP-dependent process which is decreased in the ATP-depleted settings (Parker and Gralnick, 1997). However, it seems that vWF is not a candidate marker of endothelial cell dysfunction in the setting of ATP depletion induced endothelial cell injury.

Lines of evidences demonstrated that NO level decreases in dysfunctional endothelial cells, a favored index of endothelial cell dysfunction (Kawai et al., 1996). But interestingly, NO level has never been measured as a marker of endothelial cell dysfunction in isolated ATP depleted HUVECs. In our experiment, $16.32 \%$ decrease in NO level was observed in ATP depleted when compared to untreated cells. This statistically non-significant change in NO level may be due to the fact that constellation of insults are needed for impairment of endothelial cell function, hence endothelial cells are considered as resistant cells to imposed stresses. Isolated ATP depletion may lead to aberrant endothelial cell function, synergistically, with other stressors especially by predisposing cells to further injuries. It seems that isolated partial energy deprivation may be tolerable or even considered as a sub-lethal injury by cells. The threshold of endothelial cell injury needed to perturb NO activity is not well determined, but it seems that depletion of near fifty percent of ATP stores is less pronounced to induce dramatic fall in NO production. This level of ATP depletion for cells in conditioned medium will be certainly different from in vivo conditions with complex interplay microenvironment. Determination of the threshold of ATP depletion perquisite for induction of lethal cellular injury, measurable by impaired NO production may be helpful for better understanding of ischemia and reperfusion injuries.

Consistent with previous data, isolated partial ATP depletion has not been associated with induction of apoptosis or necrosis of endothelial cells, as demonstrated by the percentage of viable cells and LDH release from treated cells (Revtyak and Campbell, 1992). Six hours of ATP deprivation, induced by simultaneous appli-cation of 2-DG and $O G$, is shown to be associated with endothelial cell dysfunction, determined by impaired synthesis of arachidonic acid (Revtyak and Campbell, 1992). We aimed to induce purinergic changes less than 
$50 \%$ ATP depletion to prevent cell death. Statistically, non-significant changes of NO and VWF secretion in our study demonstrated that candidate markers of endothelial cell dysfunction should be sought in vitro based on design of the experiment, not universally.

ATP depletion is considered as a key factor in the disruption of normal cellular transmembrane ionic gradient (Pepe, 2000). Decreased extracellular concentration of $\mathrm{Na}$, an indirect measure of increased intracellular retention, is in accordance with $\mathrm{Na} / \mathrm{K} / \mathrm{ATP}$ ase pump failure under hypoxic conditions (Palpant et al., 2008; Kawai et al., 1996). Intracellular alteration of $\mathrm{Na}$ and calcium concentrations following ATP depletion is associated with activation of inwardly rectifier $\mathrm{K}$ channels $(\mathrm{KIR})$ of high conductance, to facilitate cell membrane re-polarization (Lien et al, 2003; Mintert et al., 2007; Harrell et al., 2007; Pouget, 2008). During hypoxia, ischemia or metabolic inhibition, ATP-dependent $\mathrm{K}$ channels $\left(\mathrm{K}_{\mathrm{ATP}}\right)$ open, which facilitate $\mathrm{K}$ influx and shortening of action potential duration (Harrell, 2007; Pouget, 2008; Lebuffe et al., 2003; Cameron et al., 2003; Lascano et al., 2002). Therefore, reduced extracellular $\mathrm{K}$ concentration, following ATP depletion seems to be due to the activation of ATPdependent KIR channels, located in the membrane of endothelial cells (Cameron et al., 2003; Hu et al., 2003). The other explanation for reduced extracellular $\mathrm{K}$ concentration might be increased $\mathrm{K}$ uptake through $\mathrm{Na}-\mathrm{K}-\mathrm{Cl}$ cotransport, as seen in rat brain capillary endothelial cells (RBECs) under hypoxic conditions (Kawai et al., 1996). Membrane alteration may precede alterations in cytoplasm and nucleus. Pump failure and membrane dysfunction may be the earlier events in the process of endothelial cell dysfunction, proceeding NO impairment and VWF exocytosis.

The cascade of events involved in the process of ATPdepletion induced endothelial cell dysfunction, are not clearly identified. Further studies are needed to clarify the role of vWF exocytosis in the stressful conditions provided by isolated energy crisis for endothelial cells. Regulated secretion of VWF in graded ATP-depleted endothelial cells may give us a comprehensive insight in this regard. The lethal dose of ATP depletion for endothelial cells is more than $50 \%$. But the exact threshold needs to be determined by the grade of ATP depletion associated with impaired NO production. Besides, earlier markers of endothelial cell dysfunction should be sought, which proceed impaired NO production. So, measures such as ionic transport pump failure and arachidonic acid synthesis, as earlier markers of endo-thelial cell dysfunction, may be better alternatives in this setting.

\section{ACKNOWLEDEGMENTS}

We are highly indebted to Dr. Haghjoo for help in NO and vWF measurement, and Massah A. for his help in luminescence measurement. This study was funded by grant no. 287097 from Deputy of Research, Isfahan University of Medical Sciences, Isfahan, Iran.

\section{REFERENCES}

Arakaki N, Nagao T, Niki R, Toyofuku A, Tanaka H, Kuramoto Y, Emoto Y, Shibata H, Magota K, Higuti T (2003). Possible role of cell surface $\mathrm{H}+$-ATP synthase in the extracellular ATP synthesis and proliferation of human umbilical vein endothelial cells. Mol. Cancer Res. 1(13): 931-939.

Bassenge $E$ (1989). Flow-dependent regulation of coronary vasomotor tone. Eur. Heart J. 10: 22-27.

Burnstock $\mathrm{G}$ (1987). Local control of blood pressure by purines. Blood Vessels. 24(3): 156-160.

Buxton IL, Kaiser RA, Oxhorn BC, Cheek DJ (2001). Evidence supporting the Nucleotide Axis Hypothesis: ATP release and metabolism by coronary endothelium. Am. J. Physiol. Heart Circ. Physiol. 281(4): 1657

Cameron JS, Hoffmann KE, Zia C, Hemmett HM, Kronsteiner A, Lee CM (2003). A role for nitric oxide in hypoxia-induced activation of cardiac KATP channels in goldfish (Carassius auratus). J. Exp. Biol. 206(22): 4057-4065.

Choi HW, Barakat Al (2004). Modulation of ATP/ADP concentration at the endothelial surface by shear stress: effect of flow disturbance. Conf Proc IEEE Eng Med. Biol. Soc. 7: 5065-5068.

Dorner AJ, Wasley LC, Kaufman RJ (1990). Protein dissociation from GRP78 and secretion are blocked by depletion of cellular ATP levels. Proc. Natl. Acad. Sci. USA. 87(19): 7429-7430

El-Omar MM, Islam N, Broekman MJ, Drosopoulos JH, Roa DC, Lorin JD, Sedlis SP, Olson KE, Pulte ED, Marcus AJ (2005). The ratio of ADP- to ATP-ectonucleotidase activity is reduced in patients with coronary artery disease. Thromb. Res. 116(3): 199-206.

Figura M, Chilton L, Liacini A, Viskovic MM, Phan V, Knight D, Millar TM, Patel K, Kubes P, Giles WR, Tibbles LA (2009). Blockade of K (ATP) channels reduces endothelial hyperpolarization and leukocyte recruitment upon reperfusion after hypoxia. Am. J. Transplant. 9(4): 687-696.

Florea SM, Blatter LA (2008). The effect of oxidative stress on Ca2+ release and capacitative $\mathrm{Ca} 2+$ entry in vascular endothelial cells. Cell Calcium. 43(4): 405-415.

Harrell MD, Harbi S, Hoffman JF, Zavadil J, Coetzee WA (2007). Largescale analysis of ion channel gene expression in the mouse heart during perinatal development. Physiol. Genomics. 28(3): 273-283.

Hegeman RJ, Van Den Eijnden-Schrauwen Y, Emeis JJ (1998). Adenosine 3':5'-cyclic monophosphate induces regulated secretion of tissue-type plasminogen activator and von Willebrand factor from cultured human endothelial cells. Thromb Haemost. 79(4): 853-858.

Hinshaw DB, Armstrong BC, Beals TF, Hyslop PA (1988). A cellular model of endothelial cell ischemia. J Surg Res. 44(5): 527-537.

Holmsen H (1994). Platelet secretion and energy metabolism, in ColanRW, Hirsh J, Marder VJ, Salzman EW (eds): Hemostasis and thrombosis: Basic Principles and Clinical Practice. Philadelphia, PA Lippincott, p. 524

Hu K, Huang CS, Jan YN, Jan LY (2003). ATP-sensitive potassium channel traffic regulation by adenosine and protein kinase $\mathrm{C}$. Neuron. 38(3): 417432.

Hultén LM, Levin M (2009). The role of hypoxia in atherosclerosis. Curr. Opin. Lipidol. 20(5): 409-414.

Kawai N, McCarron RM, Spatz M (1996). Effect of hypoxia on $\mathrm{Na}(+)-$ $\mathrm{K}(+)$-Cl- cotransport in cultured brain capillary endothelial cells of the rat. J. Neurochem. 66(6): 2572-2579.

Kim JH, Yu YS, Kim JH, Kim KW, Min BH (2007). The role of clusterin in in vitro ischemia of human retinal endothelial cells. Curr. Eye Res. 32(7-8): 693-698.

Kolosova IA, Mirzapoiazova T, Adyshev D, Usatyuk P, Romer LH, Jacobson JR, Natarajan V, Pearse DB, Garcia JG, Verin AD (2005). Signaling pathways involved in adenosine triphosphate-induced endothelial cell barrier enhancement. Circ Res. 97(2): 115-124.

Köppel H, Gasser R, Pokan R, Willomitzer R, Cichocki L, Pilger E, Klein 
W (1998). Protection against myocardial ischemia by nisoldipine-an experimental study with valinomycin K-sensitive microelectrodes.

Acta Med Austriaca. 25(3): 101-105.

Lascano EC, Negroni JA, Del Valle HF (2002). Ischemic shortening of action potential duration as a result of KATP channel opening attenuates myocardial stunning by reducing calcium influx. Mol. Cell Biochem. 236(1-2): 53-61.

Lebuffe G, Schumacker PT, Shao ZH, Anderson T, Iwase H, Vanden Hoek TL (2003). Am J Physiol Heart Circ Physiol. ROS and NO trigger early preconditioning: relationship to mitochondrial KATP channel. 284(1): 299-308.

Lien YH, Lai LW, Silva AL (2003). Pathogenesis of renal ischemia/reperfusion injury: lessons from knockout mice. Life Sci. 74(5): 543-552

McCully KS (2009). Chemical pathology of homocysteine. IV. Excitotoxicity, oxidative stress, endothelial dysfunction, and inflammation. Ann. Clin. Lab. Sci. 39(3): 219-32

Mintert E, Bösche LI, Rinne A, Timpert M, Kienitz MC, Pott L, Bender K (2007). Generation of a constitutive $\mathrm{Na}$--dependent inward-rectifier current in rat adult atrial myocytes by overexpression of Kir3.4. J. Physiol. 585(1): 3-13.

Palpant NJ, Day SM, Herron TJ, Converso KL, Metzger JM (2008). Single histidine-substituted cardiac troponin I confers protection from age-related systolic and diastolic dysfunction. Cardiovasc Res. 80(2): 209-218.

Parker RI, Gralnick HR (1997). Energy-dependent expression of platelet-von Willebrand factor on the surface of unstimulated and stimulated platelets. J. Lab. Clin. Med. 130(5): 520-529

Pepe $S$ (2000). Mitochondrial function in ischaemia and reperfusion of the ageing heart. Clin Exp Pharmacol Physiol. 27(9): 745-750.

Pouget J (2008). A new type of periodic paralysis: Andersen-Tawil syndrome. Bull. Acad. Natl. Med. 192(8): 1551-1557.
Revtyak GE, Campbell WB (1992). Inhibition of prostaglandin synthesis in human endothelial cells treated with metabolic inhibitors. Biochim. Biophys. Acta. 1123(2): 216-226.

Schmitt A, Salvayre R, Delchambre J, Nègre-Salvayre A (1995). Prevention by alpha-tocopherol and rutin of glutathione and ATP depletion induced by oxidized LDL in cultured endothelial cells. Br. J. Pharmacol. 116(3): 1985-1990.

Siesjö BK (1992). Pathophysiology and treatment of focal cerebral ischemia. Part I: Pathophysiology (2008). J. Neurosurg. 108(3): 616631.

Vischer UM (2006). von Willebrand factor, endothelial dysfunction, and cardiovascular disease. J Thromb Haemost. 4(6): 1186-1193.

Zavoico GB, Ewenstein BM, Schafer AI, Pober JS (1989). IL-1 and related cytokines enhance thrombin-stimulated PGI2 production in cultured endothelial cells without affecting thrombin-stimulated von Willebrand factor secretion or platelet-activating factor biosynthesis. J. Immunol. 142(11): 3993-3999. 